\title{
Die Gesundheitssicherung im Mehrebenensystem
}

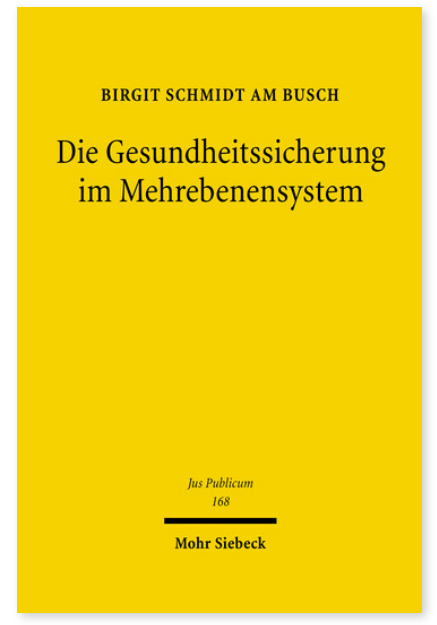

2007. XXIV, 463 Seiten. JusPubl 168

ISBN 978-3-16-151249-0

DOI 10.1628/978-3-16-151249-0

eBook PDF 129,00€

ISBN 978-3-16-149308-9

Leinen $129,00 €$
An die Stelle des Nationalstaats ist ein 'multi level government' getreten. Damit stellen sich neue rechtspolitische Herausforderungen und rechtsdogmatische Fragen. Eine Schlüsselfrage im Mehrebenensystem ist die Verteilung der Aufgaben zwischen den Ebenen.

Birgit Schmidt am Busch untersucht, ob sich Kriterien finden, die eine systematische Aufgabenzuordnung zu den jeweiligen staatlichen Ebenen ermöglichen. Als Referenzgebiet dient ihr dabei der hoch aktuelle, komplexe Bereich der

Gesundheitssicherung. Am Beispiel der vier Grundaufgaben der Gesundheitssicherung - Prävention, Kuration, Rehabilitation, Sterbebegleitung - stellt sie unter eingehender Analyse Struktur und Funktion des europäischen Mehrebenensystems dar. Ihr Augenmerk richtet sie dabei auch auf den sogenannten Dritten Sektor, d.h. auf die zwischen Staat und Markt angesiedelten Institutionen.

Die Autorin zeigt, dass sich die Aufgaben der Gesundheitssicherung auf zwei Aufgabentypen zurückführen lassen: Sie sind entweder produktbezogen, d.h. zielen auf die Eindämmung der von einem Produkt ausgehenden Gefahrenquellen für die menschliche Gesundheit (Lebensmittel), oder verhältnisbezogen, d.h. zielen auf die Bekämpfung der vom Menschen selbst ausgehenden Gefahren (Epidemien). Die Aufgabenverteilung im Mehrebenensystem hängt entscheidend davon ab, ob es sich um eine reine Wirtschaftsgemeinschaft handelt oder um ein integratives System. Die produktbezogenen Aufgaben werden in der Regel zentral wahrgenommen. In integrativen Systemen werden darüber hinaus auch die verhältnisbezogenen Aufgaben von der zentralen Ebene koordiniert, um einheitliche Lebensverhältnisse zu erzielen.

Birgit Schmidt am Busch ist Außerplanmäßige Professorin am Institut für Politik und Öffentliches Recht an der LudwigMaximilians-Universität München.

Jetzt bestellen:

https://mohrsiebeck.com/buch/die-gesundheitssicherung-im-mehrebenensystem-9783161512490?no_cache=1 order@mohrsiebeck.com

Telefon: +49 (0)7071-923-17

Telefax: +49 (0)7071-51104 